\title{
Research on the Implementation of Learning Evaluation Based on the Network Resource Teaching Platform
}

\author{
Yanqing Zeng ${ }^{1, *}$ \\ ${ }^{1}$ College of Education, Xi'an Fanyi University, Xi'an, Shaanxi 710105, China \\ ${ }^{*}$ Corresponding author. Email: 1226025420@qq.com
}

\begin{abstract}
In the context of the current information age, teaching methods based on network resource platforms have emerged. With the support of modern Internet technology, the time and space elements that restrict the traditional teaching model have been broken and the connection between teachers and students has been greatly improved. At the same time, with the help of abundant network resources, students' horizons and breadth of thinking have also been effectively expanded, and the efficiency and quality of students' learning have been greatly improved. However, what needs to be realized is that the teaching method based on the network resource platform needs to build a complete learning evaluation system, which is also a key link to improve the quality of teaching. Based on this, this article will study the relevant issues of the learning evaluation system based on the network resource teaching platform and discuss the current status, implementation methods and reflection of the current learning evaluation system, hoping to provide reference for educators.
\end{abstract}

Keywords: Network resource teaching platform, Learning evaluation, Implementation.

\section{INTRODUCTION}

In the context of the current teaching reform, the educational world is increasingly calling for the improvement of students' autonomous learning ability, and the emergence of network teaching resource platforms provides favorable conditions to support the cultivation of such ability of students. It can be said that the emergence of the network teaching resource platform has caused a great change in the teaching model, the dominant status of students in learning has been shown effectively, and the role of teachers has gradually changed from being the leader of the classroom to guiding. However, from the actual development situation, affected by factors such as students' self-control ability and learning attitude, the teaching model

*Fund: This article is the phased research result of the "Innovation and Entrepreneurship Education Reform in Colleges and Universities Under the Four New Vision" of the Ministry of Education Industry-Academy Cooperation Education Project in 2021. This article is the research result of the Shaanxi Provincial Social Science Fund Project "Research on Humanistic Care and Psychological Counseling in Ideological and Political Education of College Students in Shaanxi Province". (Project number: 2014M04) based on the network resource teaching platform needs to use a perfect teaching evaluation system to restrain students' learning behavior. Therefore, to study the implementation of the current teaching evaluation system and reflect on the aspects that still need to be improved is the main work content of the current teachers.

\section{NETWORK LEARNING EVALUATION ELEMENT SYSTEM}

\subsection{Attitude Element}

Teachers should pay full attention to the status of learning attitude in the learning evaluation system in the process of actually organizing students to carry out teaching activities. Learning attitude is a key indicator to measure the effectiveness of students' learning based on the network resource teaching platform. By examining this indicator, it can effectively help teachers understand the learning situation of students. Taking into account the differences between 
teaching based on network platform and traditional teaching, teachers need to measure students' learning attitudes by observing and recording the time when students log on to the network learning platform and the time involved in course learning in the actual work process. [1]

\subsection{Process Element}

The process of using students' inner experience to establish a knowledge structure system is the definition of the learning process in the theory of network platform teaching construction. In the actual learning process, students need to link the theoretical knowledge they have learned with the practical links, integrate the various knowledge they have learned within a limited time frame, and explore the laws contained therein to achieve a comprehensive understanding of new things from multiple angles. Therefore, the process element occupies an important position in the teaching evaluation system. Teachers can grasp the learning link of students by inspecting the learning process of students. This element mainly includes students' learning effort level and participation level and so on. Teachers can guide students to formulate targeted learning plans by collecting relevant information, and record the phased learning process and task completion performance.

\subsection{Effectiveness Element}

Students' achievement of phased learning results in the process of network learning is the element of learning effectiveness. Through the evaluation of this element, the teacher can effectively grasp the students' phased learning results and judge the students' learning effort level and learning effectiveness. The method of element evaluation is mainly divided into two methods: phased test and final test [2].

\section{LEARNING EVALUATION STRATEGY AND CONTENT BASED ON THE NETWORK PLATFORM}

\subsection{Evaluation Strategy Based on the Network Platform}

The learning evaluation strategies based on the network teaching resource platform are mainly divided into the following categories. The first is the process evaluation strategy. Teachers can evaluate students' online learning performance and their ability to solve problems. To this end, teachers can conduct comprehensive evaluations of students' autonomous learning preparation stage, learning plan and other links, and at the same time evaluate students' network learning implementation stage and interaction links so as to enhance the effectiveness of students' online learning evaluation. The second is the open evaluation strategy. In the process of evaluating students' network learning, teachers can make pertinent evaluations of students' learning attitudes and degree of participation and involvement, praise students for their positive performance, and put forward suggestions for problems existing in students' study, in order to arouse students' interest in learning and improve the quality of students' network learning. The third is the diversified evaluation strategy. Teachers should pay attention to promoting the diversified development of the evaluation system when evaluating students' network learning, encourage students to participate in learning evaluation, and use multiple evaluation methods such as self-evaluation, mutual evaluation and teacher evaluation to improve the effectiveness of evaluation.

\subsection{The Content of Network Platform Learning Evaluation}

\subsubsection{Guiding Students to Conduct Self- evaluation Before Class}

In the process of organizing students to conduct network learning, teachers should pay attention to guiding students to conduct pre-class selfevaluation, so that students can clarify their own deficiencies and formulate targeted improvement plans. Students' self-evaluation is mainly realized through test questions. Teachers can set corresponding evaluation standards on the learning platform in the actual work process to ensure that students can have an intuitive understanding of their own learning situation during the selfevaluation process, which can also help students clarify their learning goals. Students can use the self-evaluation results to develop a learning plan that meets their actual learning needs. Teachers can also clarify the actual development needs of students based on the results of students' selfevaluation and provide them with corresponding learning resources online according to the characteristics of the courses, so as to provide convenient conditions for students to learn and communicate. 


\subsubsection{Promoting Students to Conduct Phased Self-evaluation}

In the process of students' network learning, autonomous learning will run through the entire learning process of students. Therefore, network teaching platforms need to provide necessary resources based on the actual learning requirements of different students. In the learning process, students also need to use the platform to review and consolidate the knowledge points they have learned. For this purpose, teachers can set up corresponding phased test questions on the network resource teaching platform, so that it will be convenient for students to conduct self-evaluation on their own phased learning results at any time, and help students develop targeted learning plans.

\subsubsection{Scientific Use of the Results of Comprehensive Evaluation}

Comprehensive evaluation methods include student self-evaluation, process evaluation, phased evaluation and paper test evaluation, etc., which can not only inspect students' learning results, but also realize the supervision of students' learning process, ensuring that the teaching method based on network resources can achieve the unified effect of process and effectiveness.

Teachers need to realize the significance of different evaluation methods in the process of evaluating students. Encouraging students to conduct self-evaluation can ensure that students have a clear understanding of their actual situation. Good evaluation results can motivate students to further improve themselves, while pertinent evaluation can point the way for students' development. Therefore, before learning, students should first conduct self-inspection on the corresponding subjects to clarify the knowledge they have already mastered, and at the same time discover their own deficiencies, and clarify the learning goals in the following learning. This shows the importance of students' self-inspection [3].

The process assessment project is mainly composed of three parts: classroom learning performance assessment, learning assessment using network platform, and in and out of class practice project assessment. Classroom learning performance assessment mainly examines students' classroom discipline, class assignment, and class question answering and discussion. Items of learning assessment using network platform mainly include students' use rate of the platform, online learning time, discussion participation situation, the number of online homework submissions and completion status, etc. The practice project assessment mainly examines the completion rate of practice projects of students on the platform, the difficulties encountered by students in practice and the solutions, and the writing of practice report.

The paper test assessment focuses on examining students' mastery of the concepts and principles in the project they have learned. The assessment method is completed in the form of test papers.

\section{REFLECTIONS BASED ON NETWORK TEACHING EVALUATION AND RATING}

Considering that the teaching methods based on the network teaching resource platform are quite different from the traditional teaching methods, the learning evaluation process is also different, and the learning evaluation process of the network platform is relatively complicated. At this stage, the learning evaluation based on the network teaching resource platform mainly faces the following problems. First, the scientificity of student online selfevaluation needs to be further improved. Taking the online self-evaluation of students in School A as an example, after integrating the results of students' self-evaluation, the teachers found that the overall similarity of the reviews was relatively strong, and it was common for students to modify according to a unified template, which made the meaning of students' self-evaluation fail to be effectively realized, and it also showed that students had insufficient awareness of the importance of selfevaluation. Therefore, teachers should ensure that students fully realize the importance of selfevaluation when evaluating students' learning condition. Students' self-evaluation should pay more attention to the participation process, the improvement of learning ability, the formation of correct learning attitudes and the formation of values. For this reason, teachers should pay attention to the openness and diversity of learning evaluation when evaluating students. Openness lies in the fact that teachers should pay attention to breaking the constraints of time and place in the process of evaluating students, and give students corresponding evaluations in time, while the diversity lies in promoting the individual development of students through diversified evaluation methods. Therefore, the current optimization of the learning evaluation system focuses on building a complete learning evaluation 
system for the purpose of improving student learning effects.

Second, teachers should also realize the importance of summary of experience and feedback. Through interviews with teachers in School A, it can be seen that teachers didn't pay enough attention to student feedback in network platform teaching, and failed to adjust the teaching plan based on student feedback in a timely and effective manner. As a result, the interaction between teachers and students was insufficient, and students couldn't realize the importance of the experience summary. Therefore, in the actual work process, teachers should pay attention to promptly guide students to sum up their learning experience, affirm the achievements of students in phased learning, encourage students to make persistent efforts, and enhance students' self-confidence in learning. At the same time, teachers should also pay attention to guiding students to sum up their failure experiences, clarify their shortcomings, and formulate targeted improvement plans. In the process of evaluating students, teachers should pay attention to the individual differences between students, and take student development as the starting point to promote the overall development of students. At the same time, teachers should pay attention to timely giving feedback to students in the actual work process, help students clarify their own advantages and disadvantages in learning, help students form a correct understanding of themselves, and mobilize students' learning initiative.

\section{THE CONSTRUCTION OF A LEARNING EVALUATION SYSTEM BASED ON THE NETWORK RESOURCE TEACHING PLATFORM}

At the current stage, network platform teaching has become one of the current main teaching models. Taking English subject teaching as an example, most colleges and universities have opened college English courses on the network learning platform, covering English intensive reading, extensive reading, listening, writing, English culture and other resources, and the basic conditions for students' network learning have been met. Therefore, the key to the effectiveness of the current network platform learning is to improve the effectiveness of resource utilization, and as a result, the construction of an effective learning evaluation system can start from the levels of students, teachers, and schools.

\subsection{Establishing a Scientific Self- evaluation and Peer Evaluation System}

For the construction of the student-level learning evaluation system, attention should be paid to strengthening self-evaluation monitoring and quantizing peer evaluation. From the perspective of self-evaluation monitoring, students are extremely susceptible to various factors in the process of using network channels to study, resulting in limited learning time being consumed. Therefore, in the process of constructing a learning evaluation system, teachers should pay attention to guiding students to strengthen their learning management at the individual level, allowing students to record their own learning process with the help of diversified means such as electronic diary, carry out various learning activities under the guidance of clear learning goals, gradually form a good habit of completing the learning task within the required time, and make a self-evaluation of the selflearning process. This method can play a role of supervision to a certain extent, ensuring the effective use of network learning resources. Analyzed from the level of quantizing peer evaluation, the communication and interaction between students is an important part of the process of students' online self-study, and it also promotes the quality of students' learning [4]. This kind of communication and interaction not only includes cooperative learning between students, but also includes mutual evaluation among peers. Taking School A as an example, in actual work, teachers considered that students of the same grade had relatively close interactions, and evaluations within the same grade had the characteristics of multiple sources and multiple levels, so they actively promoted peer evaluation among students. From the actual effect analysis, the application of this model made the evaluation more objective and fair, and had a positive effect on the growth of students. At the same time, mutual evaluation between students of the same grade was also a way of interpersonal communication, and it also had the function of spreading tacit knowledge. In the process of actual statistical evaluation of students, the learning ability and the scientificity of learning methods were also strengthened to a certain extent. Therefore, in the process of constructing a learning evaluation system, teachers should pay attention to the degree of emphasis on the monitoring of student selfevaluation and peer evaluation, and give students 
corresponding credits on the basis of combining teacher evaluation and peer evaluation.

\subsection{Improving the Professional Quality of Teachers}

In the process of evaluating students, it is necessary for teachers to firstly change the traditional extensive monitoring methods. This requires teachers to fully realize their functions as resource builders, instructors and evaluators in online learning. At this stage, one of the reasons for the poor effect of the teaching methods based on the network resource learning platform is that teachers' extensive monitoring methods can hardly give students corresponding guidance. Meanwhile, the students' learning process lacks corresponding supervision and their learning motivation is insufficient. To this end, teachers should pay attention to formulating corresponding guidance plans according to the learning needs of students, and at the same time strengthen the supervision of students' learning process, urge students to correct their learning attitudes and actively complete learning tasks. Teachers should also pay attention to strengthening the interaction between teachers and students in the process of evaluating students. Teachers in School A used the opportunity of faceto-face teaching in actual teaching work to lay the foundation for students' online independent learning, and effectively transform the teaching experience in class and teachers' understanding of students' online learning conditions into the motivation of students' online independent study. In addition, teachers also used formative evaluation to comment on the process and effectiveness of students' online learning. Teacher evaluation belongs to the higher-level evaluation. Compared with the peer evaluation among students, teacher evaluation is more authoritative and instructive. Based on the opinions given by teachers, students made targeted adjustments to the autonomous learning plan. From the actual effect analysis, the quality of students' network autonomous learning had been effectively improved [5]. At this stage, most colleges and universities have integrated the developmental evaluation method on the basis of the summative evaluation model in the actual development process. In the actual work process, teachers use teacher observation, classroom discussion, learning report and other methods to comprehensively evaluate students' network learning situation, and effectively improve the effectiveness of the learning evaluation system.

\subsection{Giving Full Play to the Guidance Function of Schools}

In the actual development process, the school should pay attention to the impact of online teaching on students. Affected by the characteristics of rich types and large numbers of online resources, it is difficult for students to find a suitable starting point when facing online teaching resources. In addition, contemporary students have less experience in exploring learning and hands-on practice, making students lack the consciousness of independent exploration. In the actual development process, School A constantly strengthened the propaganda of relevant issues, so that students fully realized the positive role of online independent study. Students had a deeper understanding of the network resource platform, and autonomous learning activities carried out on this basis had a better effect, and the improvement of the learning effect was also more obvious. In addition, the school also continuously strengthened the management of teachers. As the main builder of learning resources in the independent study of the network platform and the guider of students in the learning process, teachers play an important role in the learning evaluation system based on the network resource teaching platform. The school must be fully aware of the pressure of teachers in daily life, professional title evaluation and other aspects while taking on the heavy responsibility of teaching. [6] This kind of pressure is also the main reason for the extensive supervision model of teachers in the process of evaluating students' learning achievements. Therefore, the school need to continuously strengthen the construction of teacher's ethics in actual work to ensure that teachers face the work of learning evaluation with the correct attitude, and effectively improve the effectiveness of evaluation work.

\section{CONCLUSION}

To sum up, China's learning evaluation based on the network resource teaching platform mainly includes two evaluation strategies: process evaluation strategy and open evaluation strategy, and three evaluation methods of students' pre-class self-evaluation, staged self-evaluation and comprehensive assessment. The current learning evaluation system mainly has problems such as insufficient scientificity of student self-evaluation and untimely feedback from teachers. Therefore, in the process of optimizing the learning evaluation system based on the network resource teaching 
platform, China should pay attention to starting from the three levels of students, teachers and schools, enhancing the scientificity of student selfevaluation and mutual evaluation of students of the same grade, strengthening the communication between teachers and students, and optimizing teacher monitoring methods, providing effective motivation for students to learn independently on the Internet. Meanwhile, schools should pay attention to strengthening publicity to ensure that students fully realize the importance of independent study on the Internet, strengthen the management of teachers, and provide a strong guarantee for improving the effectiveness of the learning evaluation system.

\section{AUTHORS' CONTRIBUTIONS}

This paper is independently completed by Yanqing Zeng.

\section{REFERENCES}

[1] Li Dandan. Research on online course evaluation system based on network teaching platform [J]. Telecom World, 2019, 345(02): 290-291. (in Chinese)

[2] Liu Hanmei, Xu Yongsu, Zhang Yongmei, et al. Application of formative evaluation based on network teaching platform in course assessment — taking adult nursing as an example [J]. China Higher Medical Education, Issue 9, 2020, pages 69-70, 2020. (in Chinese)

[3] Liu Qiu, Chen Chao, Liu Changjian, et al. Content design and teaching effect evaluation of Microbiology course based on the construction of network teaching resources $[\mathrm{J}]$. Microbiology China, 2020, 047(004): 11171125. (in Chinese)

[4] Zou Yun. Research and Practice of Using Network Teaching Platforms to Implement Process Assessment [J]. Vocational Education Research, 2020, 194(02): 65-69. (in Chinese)

[5] Luo Yali. Evaluation of digital teaching based on "Jincheng Online" network teaching platform [J]. Digital Space, 2019, 170(12): 204-204. (in Chinese)

[6] Li Fajuan, Talking about the "College English" course under the application-oriented talent training model based on the SPOC teaching development and application research in the post-MOOC era [J]. Tea in Fujian, 2020 vol.42 (1). (in Chinese) 